\title{
Competencias laborales de deportados
}

Elsa Ramos

Investigadora, Dirección de Investigaciones de la UTEC

\section{Resumen}

El núcleo central del presente trabajo de investigación está dedicado a explorar qué tipo de trabajo desempeñaban las personas deportadas antes de emigrar y los trabajos en que se desempeñaron una vez ubicados en los Estados Unidos de América (EE.UU.). Realizar una comparación y detectar cuáles son las competencias laborales que adquirieron en ese país. Así se pudo observar que la mayoría de personas emigrantes se dedicaban predominantemente a la agricultura, a la construcción y al estudio; en cambio los trabajos desempeñados en EE.UU., la mayoría se dedicó a la construcción, a los servicios en el área de la restaurantería (meseros, cocineros) y empleados de diversas áreas, pero en general nada relacionado a lo que se dedicaban en El Salvador. La mayoría respondió que se consideraban mejor capacitados en los trabajos que desempeñaron en aquel país. Un porcentaje bastante alto aprendió inglés. Estas personas deportadas se podrían integrar a trabajar en el país a partir de las competencias laborales adquiridas. No se tendría que invertir en su capacitación y además ellos contribuirían al traspaso de las normas de calidad que se practican en ese país. El trabajo está estructurado por marco teórico; aspectos metodológicos; las estadísticas oficiales; análisis del trabajo de campo con deportados vía aérea y resultados.

\section{Palabras claves:}

Migración, deportados, flujo migratorio, programas de empleo, competencias laborales.

\section{Introducción}

$\mathbf{F}$ tema migratorio al transversalizar todos los ámbitos de la sociedad salvadoreña se transforma un tema de nación, que hace necesario y pertinente continuar estudiándolo para profundizar más en su conocimiento, pues las migraciones internacionales del país han creado a un nuevo país "un nuevo nosotros" (PNUD, 2005). Investigaciones como esta pueden constituir insumos para la creación políticas públicas y los programas y proyectos necesarios para solucionar los problemas que surgen como consecuencia del fenómeno migratorio y que también dan luces para paliar en alguna medida el flujo migratorio imparable a corto plazo. $\mathrm{P}$ ara que los salvadoreños y salvadoreñas dejen de emigrar se necesita transformar al país, dejar de aplicar las políticas neoliberales como se ha hecho en las últimas dos décadas; refundar al país bajo nuevos principios de justicia, equidad de género y distribución equitativa de la riqueza nacional y otras medidas, en donde haya un pacto entre gobierno $y$ empresa privada para la implementación de programas de creación de empleos en cantidad y calidad, o sea, de acuerdo al número de personas que se incorporan anualmente al mercado laboral y la inclusión de las personas en desempleo abierto y subempleo, salarios dignos que satisfagan todas las necesidades básicas de los salvadore- ños. En pocas palabras, la generación de empleos decentes.

Se debe tener claridad que la emigración e inmigración son fenómenos que no es fácil de solucionar. La migración es un problema estructural, por ende se insiste que es necesario realizar cambios estructurales, para que la emigración deje de ser la única salida que están encontrando los salvadoreños para obtener una vida digna. Las mismas personas deportadas son de la opinión que no importan los sacrificios para emigrar, no importa que los trabajos sean duros, pero los buenos salarios hacen que valga la pena sacrificarse. "No importa trabajar como 


\section{Abstract}

The core of this research is dedicated to explore what type of work performed deported persons before emigrating and the jobs that are performed by them once located in the United States of America (USA), to compare and identify what are the job skills they acquired in that country. Thus it was observed that most emigrants are predominantly engaged in agriculture, construction and study, but instead, the works done in the U.S., most of them devoted to construction, services, to the catering industry (waiters, cooks) and employees of different areas, but in general nothing related to what they used to do in El Salvador. Most of them said they considered themselves better trained in the work they performed in that country, a fairly high percentage learned English. These deportees could be integrated to work in the country from the work skills acquired. No one would have to invest in their training and they also contribute to the transfer of quality standards that are practiced in this country.

The work is structured by theoretical framework, methodological aspects, the official statistics, and analysis of field work with air deportees and results.

\section{Key words:}

Immigration, deportation, migration flow, employment programs, job skills.

burro", se escucha a través de las entrevistas realizadas. La migración debe de transformarse en una opción voluntaria, no la única salida a los problemas económicos que enfrenta la población salvadoreña.

Es para contribuir a la profundización del conocimiento de un subtema de la realidad migratoria que se realizó esta investigación y para presentar una pequeña propuesta que ayude a aliviar la dura situación que deben enfrentar las personas deportadas al llegar al país.

Una investigación de este tipo es importante para esclarecer y procurar borrar la gran cantidad de prejuicios y mitos con respecto a las personas deportadas, por ejemplo muchas personas los perciben como fracasados, malvivientes, viciosos, ladrones, mareros. Muchas de las personas deportadas, que no son mayoría, al llegar al país en alguna medida se sienten fracasadas, "que no la hicieron"; desanima- das al tener que enfrentar nuevamente la difícil situación económica del país, agravada con la ola de violencia social y delincuencial en la cual está inmersa la sociedad salvadoreña.

Es necesario nuevamente señalar que la causa principal por la que los y las salvadoreñas emigran es por razones de indole económica, entre las cuales se pueden señalar las siguientes: gran números de salvadoreños/ as emigran no porque falta de empleo, sino porque los salarios que devengan no suplen ni siquiera las necesidades básicas de sus familias, lo que indica la falta de trabajos decentes o que permitan llevar una vida digna, entre la mayoría de los/as asalariados/as salvadoreños/as; a los jóvenes que recién se incorporan al mercado laboral sean profesionales o no, se les hace sumamente difícil ingresar a este, lo que señala la falta de oportunidades en el país. Hechos que a la larga los sume en el subempleo y los inclina a pensar que en el país no se pueden superar. alcanzar a realizar sus proyectos de vida. Otra causa que en estos momentos esta tomando relevancia es el alto índice de violencia social y delincuencial, que se ve reflejada en el alto grado de crímenes violentos que incluso en el mes de octubre del 2009 alcanzó la cifra de 16 personas asesinadas por día, lo que convierte a El Salvador en uno de los países más violentos de América Latina. Así por ejemplo, se

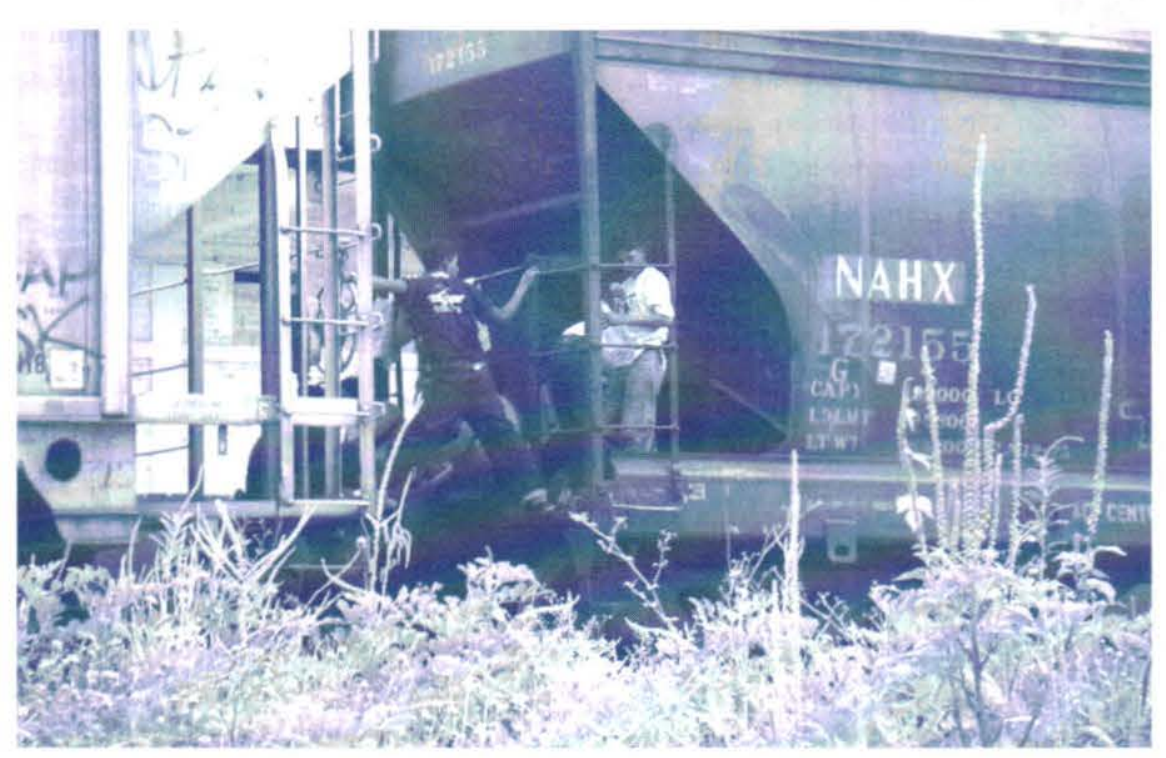




\section{La migración}

es un problema

estructural, por ende se

insiste que es necesario

realizar cambios

estructurales para

que la emigración deje

de ser la única salida

que están encontrando

\section{las y los salvadoreños para obtener una vida digna.y5}

ha transformado en una práctica común de las maras (pandilleros) reclutar a sus nuevos miembros no de forma voluntaria, por atracción a su forma de vida por parte de los adolescentes, sino que están obligando a los y las jóvenes a incorporarse a estas bajo la amenaza de que los asesinan a ellos o sus familiares, razón por la cual muchos padres y madres de familia optan por enviar a sus hijos e hijas fuera del país y en especial a EE.UU. tengan o no parientes y amigos que los reciban, pues consideran que de esa forma están salvaguardando la integridad física de sus hijas e hijos.

Al realizar la presente investigación, los que son regresados a la fuerza porque generalmente infringieron las leyes de los países receptores, no necesariamente porque hayan cometido delitos graves, su principal falta es llegar de forma irregular y permanecer en esos países de forma indocumentada. En su mayoría son personas honradas, decentes, que lo único que persiguen es percibir salarios superiores a los que reciben en sus países de origen y con ello mejorar la calidad de vida de sus familias que han quedado atrás.

Las personas que emigran aparte de ser personas dignas $y$ honestas son personas caracterizadas por su intrepidez, valentía, emprendedurismo, pues al emigrar van dispuestas a trabajar en lo que sea, aprender lo que sea y poder emplearse en los países receptores; trabajar dos o tres turnos si es necesario para enviar la cantidad de remesas suficientes para pagar las deudas que han dejado en el país. Por ejemplo, pagar sus tarjetas de crédito, pagar hipotecas de sus casas, saldar la deuda con el coyote, entre otras. Por supuesto mejorar la calidad de vida de su familia, que se ve reflejado en primer lugar en la mejora de la dieta alimenticia, la incorporación de todos los hijos e hijas a estudiar; comprar vivienda, si es que no se cuenta con ella o mejorar la que ya tienen, coadyuvando con ello incluso a la generación de empleo local.
Las personas deportadas injustamente están siendo percibidas como delincuentes. Hay que tener en cuenta que la mayoría de ellos no los capturan recién llegan a los EE.UU., sino que ya tienen años de residir en ese país y han contribuido a la economía nacional a través de sus remesas, que a su vez al ser gastadas pagan el Impuesto al Valor Agregado (IVA). Las Ilamadas telefónicas al exterior están gravadas con $\$ 0.04$, lo anterior solo para dar algunos ejemplos. Las mismas personas deportadas al ser entrevistadas hacían referencia que sus familiares los iban a recibir con gusto porque ellos habían enviado "religiosa y mensualmente" remesas, que no sentían vergüenza que los hayan deportado. Muchos de ellos al expresarse acerca de las labores que desarrollaban en EE.UU. se mostraban también orgullosos de todo lo que habían aprendido, parte de ello era referirse a sus trabajos en donde utilizaban el inglés y los encuestadores al preguntarles a que se referían, les explicaban, qué hacían y cómo lo ha-

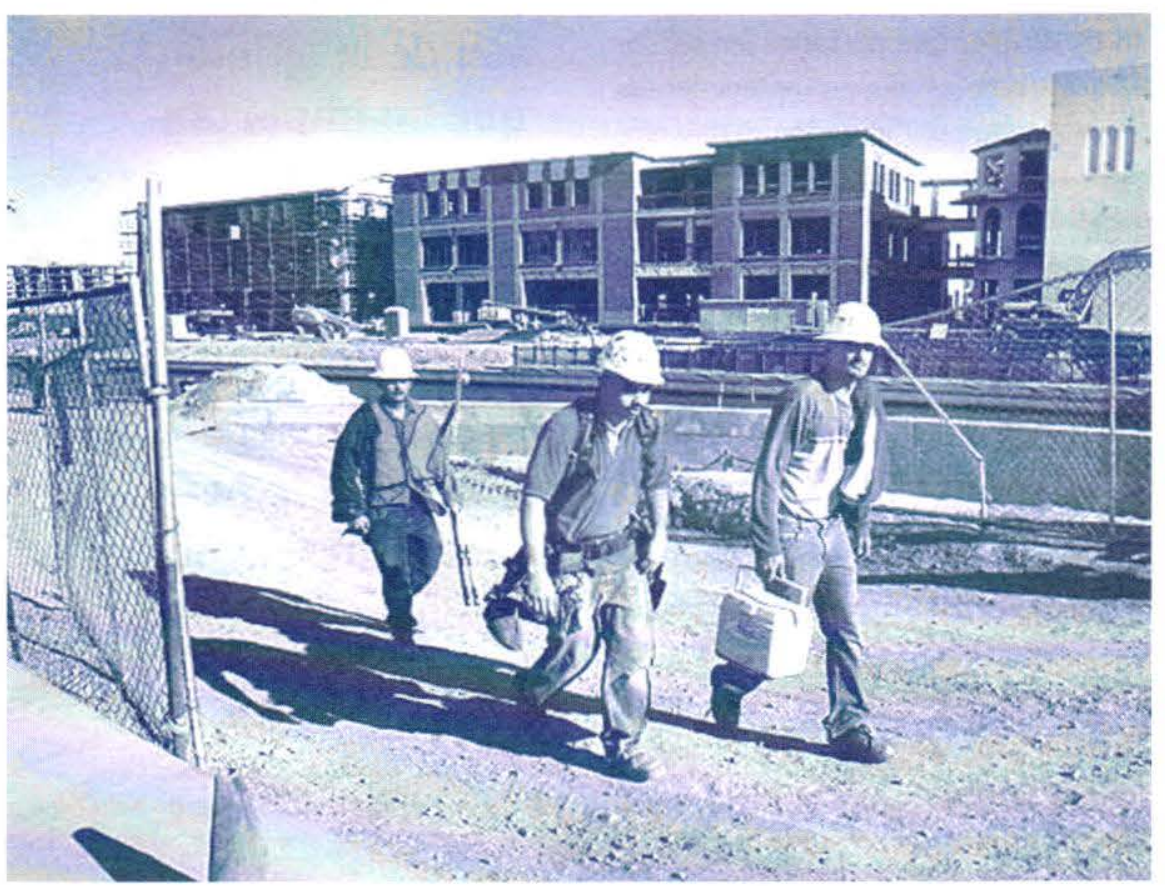


cían. La otra cara de la deportación son las personas que han cometido delitos en EE.UU.: se mostraban huraños, recelosos, pero cuando observaban que no se les hacían preguntas acerca de si tenían o no antecedentes criminales, algunos de ellos accedían a contestar la encuesta.

Desde el punto de vista metodológico, la presente investigación es exploratoria porque no hay estudios de referencia en el país y muy pocas en el extranjero. Es de tipo cuantitativo y cualitativo, ya que se aplicó un cuestionario a las personas recién deportadas en las afueras del Programa Bienvenido a Casa y se realizaron una serie de entrevistas semiestructuradas a personas deportadas, que por lo menos tuvieran un año de haber sido deportadas. La muestra fue de tipo intencional, ya que las dificultades para obtener las encuestas y las entrevistas limitaron la realización del trabajo de campo.

En el apartado acerca de las estadísticas oficiales fue escrito con el objetivo de develar que no todas las personas deportadas tienen antecedentes penales y que por lo tanto, no hay ninguna razón para estigmatizarlos, para culpabilizarlos por el aumento desmedido de la delincuencia, extorsiones, el desarrollo del fenómeno de las maras (pandillas) en el país.

Se debe de señalar que los datos estadísticos ofrecidos por el Ministerio de Justicia y Seguridad Pública, carecen de grandes vacíos entre los cuales se pueden mencionar los siguientes: se ofrecen datos solo a partir del año 2004, dichos datos no ofrecen rangos

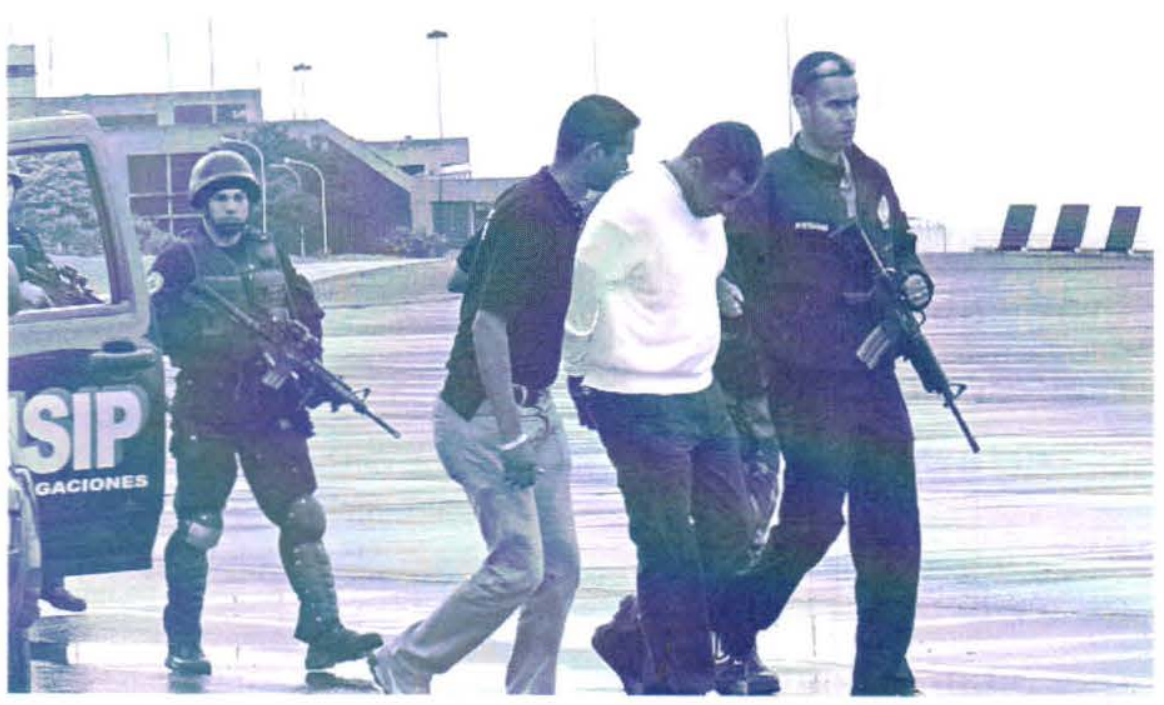

de edad, estado civil, clasificación por género pero el dato que no olvidan es señalar las personas deportadas con y sin antecedentes penales. No obstante estos datos se tomaron como parámetros. Se obtuvo que del año 2004 al mes de agosto del año 2009 llegaron al país 82,140 personas deportadas de

9 Las mismas
personas deportadas
son de la opinión
que no importan
los sacrificios para
emigrar, no importa
que los trabajos
sean duros, pero los
buenos salarios hacen
que valga la pena
sacrificarse, pues no
importa trabajar como
burro.

todas partes del mundo, de ellas solo 23,632 contaban con antecedentes penales, o sea, apenas un $28,77 \%$ del total, mientras tanto 58,574 personas deportadas no contaban con antecedentes penales, que equivalen al $71,27 \%$ de personas deportadas.

En cuanto a las personas deportadas vía aérea de los EE.UU. ${ }^{1}$ a partir del año 2006 hasta el mes de agosto del año 2009, se obtuvo el dato que fueron 67,635 personas, de ellas solamente 19,836 que equivalen a un $29,32 \%$ contaban con antecedentes penales. En cuanto a las personas deportadas sin antecedentes penales sumaron 47,495, que representan el $70,67 \%$. Vale la pena resaltar que de las personas deportadas con antecedentes penales, solamente 266 de ellas fueron deportadas por pertenecer a pandillas, si se observan las cifras en general se puede afirmar que no hay una base estadística que demuestre que el aumento de la delincuencia, la violencia y la actividad de las pandillas en el país

\footnotetext{
1 Los porcentajes aquí presentados han sido trabajados por la autora a partir de los datos presentados en: Control de salvadoreños deportados con y sin antecedentes penales, años 2004 al 2009 Ministerio de Justicia y seguridad Pública en http://www.seguridad.gob.sv/ Web-seguridad/Migracion/deporta...
} 
es un resultado directamente proporcional al números de personas deportadas con antecedentes penales. No está demás señalar también que una buena cantidad de personas deportadas con antecedentes penales no han cometido faltas graves en los EE.UU. y que incluso esas faltas leves en El Salvador ni siquiera son consideradas como delitos, por lo cual se hace necesario realizar una reevaluación para quitarles el estigma a las personas deportadas como culpables directos del aumento de la delincuencia, violencia social y la actividad como pandillero. Exigir a las autoridades de migración y extranjería basarse en las estadísticas y estudios a profundidad para emitir opiniones más justas y equilibradas en relación a la población deportada, lo mismo que los medios de comunicación social que se preocupen en realizar periodismo de investigación y no se limiten a repetir de forma mecánica las declaraciones de dichos funcionarios, porque ello afecta de manera significativa a las personas deportadas que sin excepción se les ha creado una imagen negativa.

Es interesante añadir que de acuerdo a los datos oficiales los cinco departamentos que reciben más deportados son los siguientes: San Salvador (8,556); San Miguel $(8,254)$; Usulután (6,640); La Unión $(6,250)$ y Santa Ana (5,884). Al observar las cifras anteriores que pueden ser un reflejo de la cantidad de personas que emigra por departamento, se podría inferir que la zona oriental sigue ocupando el primer lugar en emigración, pero que el departamento de San Salvador ha tomado la delantera y Santa Ana de la zona occidental ha entrado al rango de los mayores expulsores de población por lo cual se hace necesario realizar un mapeo de las migraciones en el país.

Del análisis del trabajo de campo con deportados vía aérea desde los EE.UU., los datos más relevantes que se obtuvieron son que los rangos de edad de las personas que están siendo deportadas son de los 21 a los 25 años de edad y de los 26 a los 30 años de edad, con un equivalente del $22,53 \%$ y un $20,65 \%$ respectivamente, lo que significa que dichas personas están en plena edad productiva y reproductiva. Se obtuvo que el 61,97 de las personas deportadas al emigrar eran solteras/os y que un 32,82 sí ya habían adquirido compromisos familiares, lo que implica que al emigrar estos últimos crearon un duelo migratorio no solo de sus progenitores sino de sus esposas (o compañeras de vida) y de los hijos/ as que dejaron atrás. Otro $43,85 \%$ de personas deportadas formaron sus familias en los EE.UU., lo que a su vez implica un desgarro familiar ocasionado por la deportación de estas personas.

En cuanto al estatus migratorio de las personas deportadas, el $71,83 \%$ de ellas estaban de forma indocumentada de los EE.UU., en cuanto si contaban o no con antecedentes penales no se investigó como estrategia para obtener la mayor cantidad de encuestas posibles, porque si no las personas se sienten agredidas.

Con respecto a los datos laborales y las competencias laborales adquiridas en los EE.UU. por las personas deportadas, se obtuvieron los siguientes datos: las ocupaciones laborales de las personas antes de emigrar fueron muy diversas y en diferentes áreas laborales, se han tomado como más significativas las que alcanzaron mayor número de personas ocupadas en dicho oficio u ocupación, se tiene así que en las labores agrícolas fue un 15,02\% (32 personas); $12,07 \%$ (27 personas) eran estudiantes y un $9,85 \%$ (21) trabajaban en el área de la construcción; habian

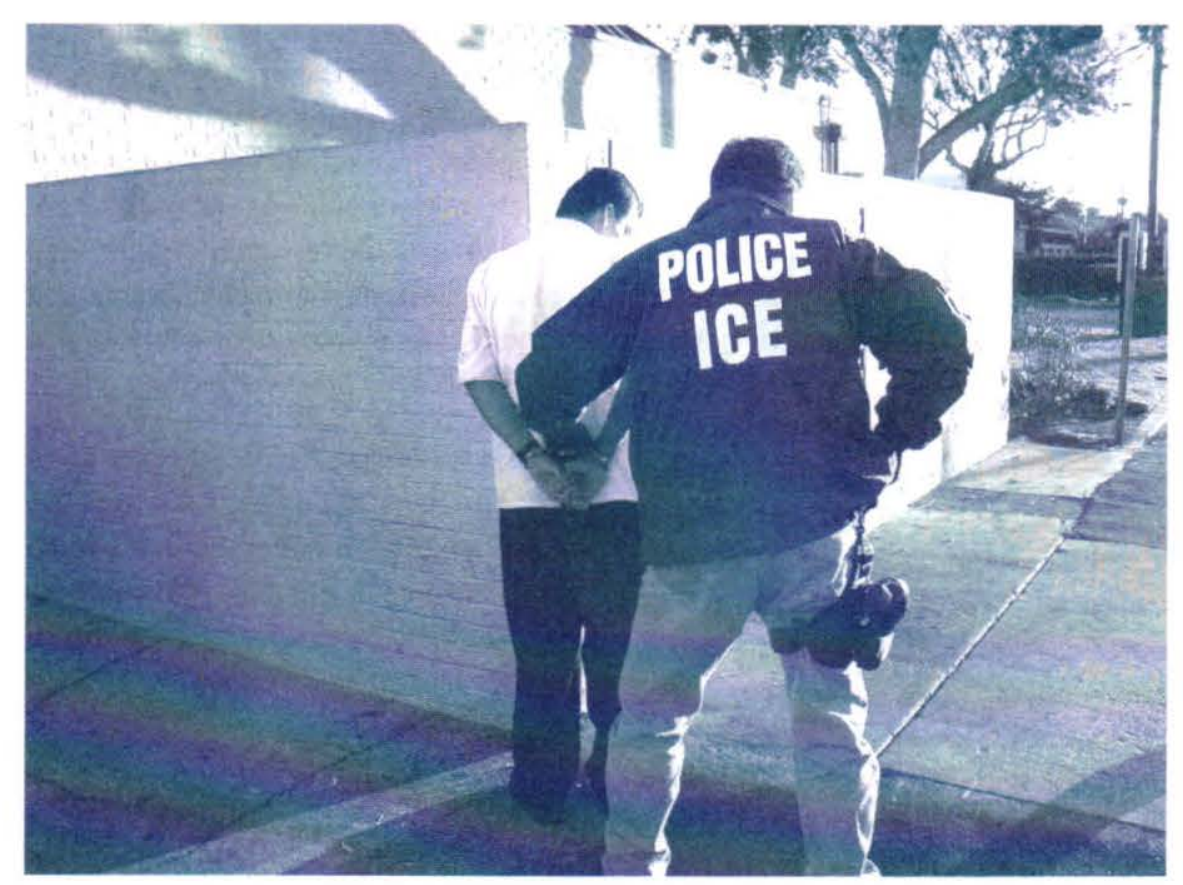




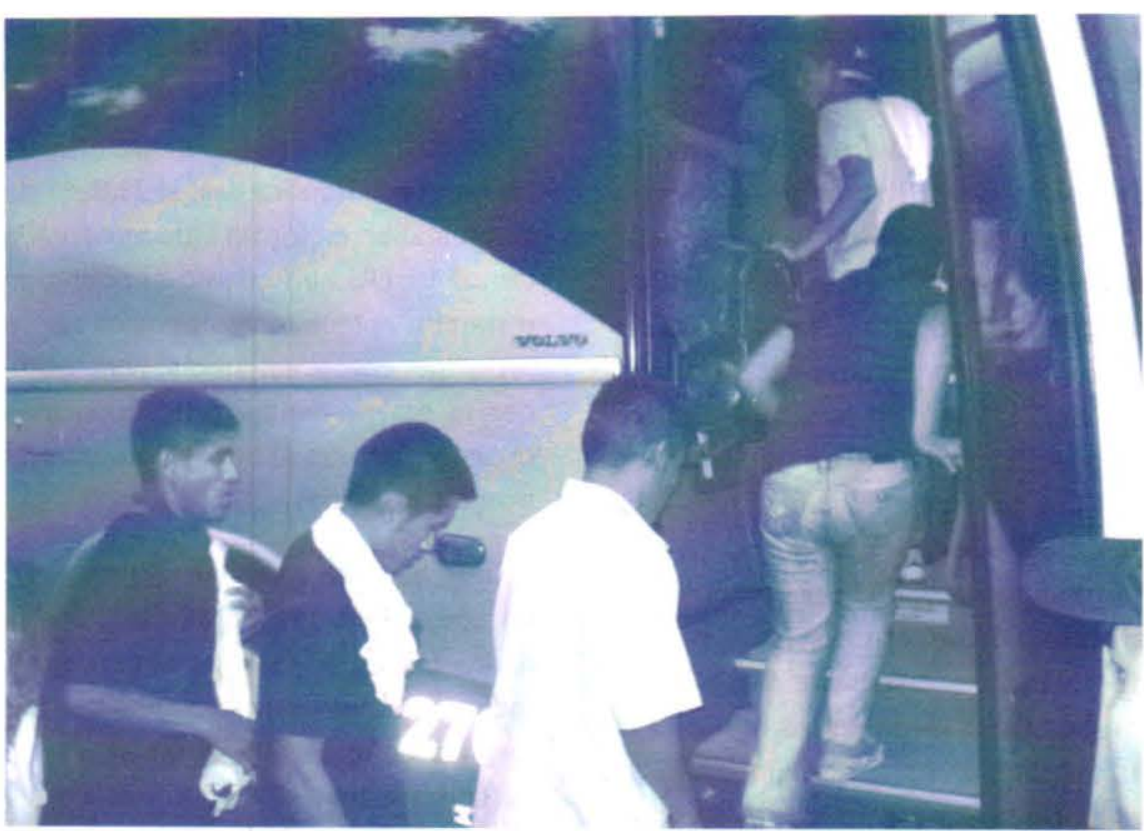

desempleados, personas que emigraron cuando eran menores de edad, trabajadores de talleres de mecánica y muchos oficios más. En cuanto a los trabajos que desempeñaron en los EE.UU., también fueron muy diversos y en diferentes áreas, pero con prevalencia en dos áreas en especial: la construcción y los servicios (restaurantería y hotelería), obteniéndose que por ejemplo 55 personas ofrecieron como única respuesta que trabajaron en la construcción; solo 3 personas eran estudiantes y 4 personas se dedicaron ala agricultura (pizca), lo anterior se trae a colación pues son las ocupaciones que más fueron mencionadas antes de emigrar y se nota la diferencia que las cifras disminuyen en cuanto a las personas dedicadas a la agricultura y los que eran estudiantes y se incrementa de forma superlativa los trabajadores de la construcción. Es más, hay deportados que contestaron haberse desempeñado en dos o tres oficios como en construcción/carpintería; construcción/chef y otros, o sea, totalmente diferente a lo que se habían dedicado en el país.
Otra pregunta importante que se les realizó, y que atañe a las competencias laborales adquiridas en EE.UU., es en qué oficio se consideraban ellos más capacitados para poderse integrar laboralmente en el país. Prácticamente todos y todas sin excepción testificaron que se consideraban más aptos laboralmente en los oficios desempeñados en aquel país. O sea, las personas deportadas están muy seguras de lo que aprendieron allá y por lo tanto se puede considerar que adquirieron nuevas competencias laborales, entendida esta última como la capacidad real de desempeñar exitosamente una labor sin temor a equivocarse y que se aprendió de la práctica misma.

Y para finalizar se detectó que entre las personas deportadas un $84,21 \%$ (144 personas) manifestó que aprendió a hablar inglés. De ellas, 80 personas solo lo hablan y 60 personas lo hablan y los escriben.

Los datos arriba mencionados dan luz para poder prever en un futuro cercano se pueden implementar pro- gramas de reinserción laboral con las personas deportadas partiendo de las competencias laborales adquiridas en Ios EE.UU., y su capacidad de poder expresarse de forma verbal o verbalmente y de forma escrita en el idioma inglés, con lo cual el gobierno y sus agencias ahorrarian grandes recursos económicos y tiempo, con la ventaja también que estas personas pueden transmitir a las áreas laborales y compañeros las habilidades y destrezas y normas de calidad utilizadas en ese país extranjero.

\section{Algunas conclusiones}

El tema de las personas deportadas, aún con el nuevo gobierno, sigue siendo tratado como tema de seguridad nacional. A estas personas se les continua acusando sin justa razón de ser los responsables o culpables del aumento de los índices de violencia en el país. No se tiene la voluntad política de ir más allá y buscar esas causas dentro de la propia sociedad salvadoreña.

\section{Muchas de las}

personas deportadas,

que no son mayoría, al llegar al país en alguna medida se sienten fracasadas, "que no la hicieron"; desanimadas al tener que enfrentar nuevamente la difícil situación económica del país. 


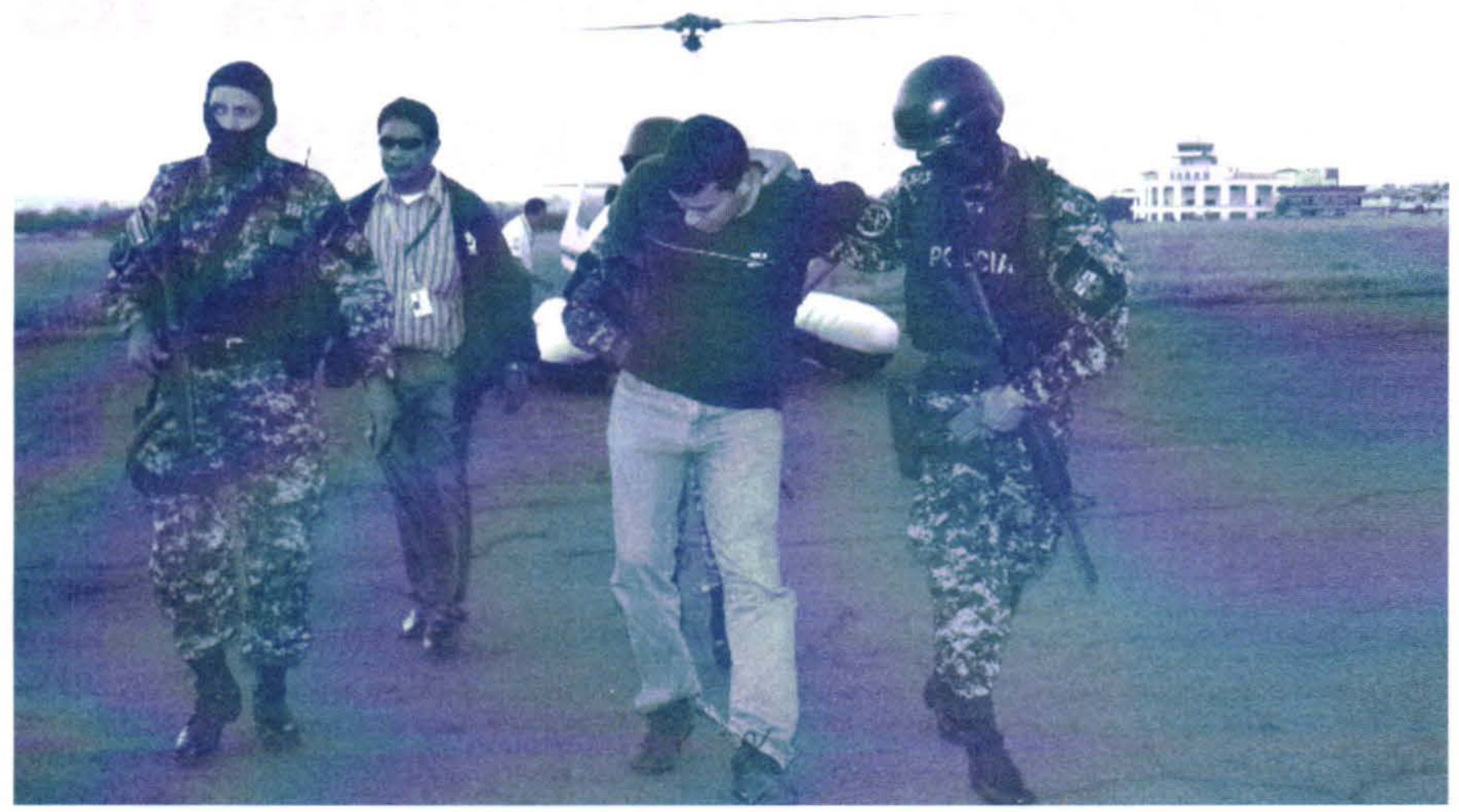

La deportación se puede asociar con los procesos de reemigración que está generada por diferentes causas entre las cuales se puede mencionar la reunificación familiar de los deportados que dejaron a sus familias en los EE.UU.; por la falta de oportunidades laborales; las personas después de vivir muchos años en otro país ya no se adaptan al suyo; porque ya tienen una concepción diferente de la vida; porque ya adoptaron el modo de vida norteamericano.

\section{Algunas recomendaciones:}

- Acercar a todos los departamentos los programas de capacitación ofrecidos por el Programa de Repatriaciones de la dirección de Migración y Extranjería.
- Que el gobierno central, a través de la Cancillería, establezca una carta compromiso con el gobierno de los EE.UU. que garantice la recuperación de los bienes muebles, ahorros y demás de las personas deportadas que han residido por varios años en ese país y que no tengan antecedentes criminales $y$ las que sí los tienen pero que no son graves, que les permita reiniciar su reintegración a la vida económica del país a partir de lo que ganaron honradamente en dicho país.

- Establecer alianzas, convenios, cartas de entendimiento con las organizaciones de la sociedad civil para trabajar proyectos de desarrollo local sostenible con la incorporación de deportadas y deportados, aprovechando las habilidades $y$ el emprendedurismo desarrollados por ellas y ellos en EE.UU.

\section{Bibliografía:}

- Control de salvadoreños deportados con y sin antecedentes penales, años 2004 al 2009. Ministerio de Justicia y seguridad Pública en http://www.seguridad.gob. sv/Web-seguridad/Migracion/deporta...

- Programa de las Naciones Unidas para el Desarrollo (PNUD). Informe de Desarrollo Humano 2005: una mirada al nuevo nosotros, el impacto de las migraciones / PNUD; coordinador William Pleitéz - $1^{\text {a }}$ edición - San Salvador, El Salv.: PNUD, 2005. 